\title{
Happiness and health: two paradoxes ${ }^{1}$
}

\author{
Simone Borghesi
}

(University of Pescara)

Alessandro Vercelli

(University of Siena)

Provisional draft: 25.10.07

\section{Introduction}

The causal interaction between happiness and health is well documented. The empirical evidence shows that self-reported happiness of people depends closely on their perceived health status. Although individuals have a remarkable capability of adaptation to health shocks, even very serious ones, the adaptation is almost never complete. On the other hand, the empirical evidence shows that the perceived happiness of individuals deeply affects their health status. People who feel happy enjoy a better health, while unhappiness deteriorates the state of health reducing the immune resistance and originating psychosomatic diseases that may lead to depression and suicide.

The socio-economic determinants of happiness and health have been extensively studied in the last decades, although almost always separately, by different communities of researchers: mainly economists and psychologists in the case of happiness, mainly social epidemiologists in the case of health. We intend to show that the analysis of the relationships between these two rapidly growing streams of empirical analysis may be illuminating for both of them helping us to understand better the relationship between happiness, health, their determinants and their policy implications.

The structure of the paper is as follows. In the second section we argue why in this work we chose to focus on the interaction between subjective indexes of happiness and objective indexes of health. In section 3 we examine the main determinants of subjective happiness in the light of recent empirical evidence accumulated by economists,

\footnotetext{
${ }^{1}$ We wish to thank the participants in the Conference "Policies for Happiness" held at the University of Siena, 14-17 June 2007) for their useful comments. All the remaining shortcomings are our responsibility.
} 
psychologists and sociologists. In section 4 we consider the main determinants of objective health in the light of the contributions by social epidemiologists. In section 5 we discuss the twin paradoxes concerning on the one hand the relationship between subjective happiness and income and on the other hand the link between subjective happiness and objective health indexes. In section 6 we focus on the shortcomings of the empirical indexes of both subjective happiness and objective health. Section 7 briefly comments on the empirical and policy relevance of the results emerging from the comparative analysis of the two streams of literature on happiness and health.

\section{Indexes of happiness and health}

We can define a whole spectrum of measures of (un)happiness that ranges between two extremes: objective measures based on the direct observation of physiological states, and subjective measures based on the direct assessment of individuals (see Frey and Stuzter, 2002). At one extreme we have subjective measures based on self-reported evaluations. These measures are at the center of the happiness literature. At the other extreme we have objective measures in the strict sense of the word based on the controlled observation of asymmetric brain waves (ibidem). We have then a grey zone where selfreported measures are corrected of their subjective distortions. In this sense they are also sometimes called "objective”. The most rigorous attempt of this kind is that pursued by Kahneman and collaborators who start from instantaneous subjective assessments, considered more reliable than assessments of remembered experiences, and devise procedures of integration that reduce the subjective biases (Kahneman, 1999). This research stream made progress in the last years but is far from being completed. In this work we ignore the objective measures of happiness as their methods are still under scrutiny and the empirical evidence produced is still insufficient for our comparative purposes

In the case of health we have subjective indexes in a sense analogous to that of subjective indexes of happiness. Indexes of self-reported health are now regularly updated on the basis of periodic surveys that allow cross-section and time-series analysis of its determinants and its correlations with other variables. The correlation between selfreported health and subjective happiness is very high. For example Kahneman and Riis (2005) found a correlation coefficient $r=0.85$ in the 18 OECD countries analyzed. This confirms the pre-eminent subjective importance attributed by individuals to health in their self-assessment of happiness. However, the sources of the subjective evaluations of both 
happiness and health are only weakly independent as both are strongly conditioned by the personality and culture of the individual who assesses them. This explains why selfreported health was found only weakly correlated with objective measures of health in the same OECD countries mentioned above.

In this paper we prefer thus to focus on the links between indexes of subjective happiness and indexes of objective health in order to study the interaction between factors that may be considered as sufficiently independent to justify a causal analysis. The analysis of a population health status is generally based mainly on objective indexes such as life expectancy measured at a certain age or mortality rates for different groups of people and different causes or set of them. These indexes are objective in a fairly strong sense, as they are based on the direct observation of empirical events such as death and diagnosed illnesses. A third important category of health indexes are quality-adjusted life expectation indexes that integrate mortality and morbidity indexes with other indexes of life quality to express health status in terms of equivalents of well years of life. In this paper we will ignore this category of indexes, notwithstanding their obvious appeal, since their availability is still limited and their use is still controversial for unsettled methodological questions (see, e.g., the recent survey by Hansen and Østerdal, 2006).

The objective health indexes are no doubt partial indexes of subjective health as they cannot cover the whole range of factors that affect it. They are able, however, to capture the impact of a few factors particularly important for subjective health. In particular, they implicitly take account of unconscious sources of happiness that by definition do not emerge in subjective assessments. This may help us to study the distortions of self-reported health and related distortions in subjective happiness.

\section{The determinants of subjective happiness: the first paradox}

In this section we aim to discuss the main determinants of subjective happiness in the light of the empirical evidence accumulated in the last decades as a benchmark for the comparison with the determinants of health.

\subsection{The role of absolute income and income aspirations.}

Cross-section analysis generally detects a positive correlation with a decreasing slope between subjective happiness and per capita income both between countries and within countries for different classes of income. An increase in per capita income $Y$ seems to increase significantly subjective happiness $W^{*}$ only for very low classes of income; this 
impact tends to diminish for higher income classes and to fade away after a threshold around $\$ 10,000$ (according to Frey and Stutzer, 2002) or $\$ 15,000$ per year (according to Layard, 2006):

$$
W^{*}=f_{1}(Y), \quad f_{2}{ }^{\prime}>0, f_{2}{ }^{\prime}<0
$$

However, if we analyze the evolution of reported subjective happiness in developed countries after WWII, the correlation with per capita income is generally nonexistent or slightly negative in apparent contradiction with the predictions of standard utility theory. This result was first found by Easterlin (1974) for the USA and subsequently confirmed for other developed countries such as the UK, Japan, France, Germany, Netherlands (Easterlin, 2001). The decoupling between the empirical trends of income and self-reported happiness is often referred to as the "happiness paradox". In fact, an increase in personal income extends the set of goods that may be purchased and consumed and this is supposed to improve the total utility (or happiness) of rational agents. The paradox becomes even more surprising if we accept the conviction of traditional utilitarian economic theory that the relevant measure of welfare is consumption not income, since consumption propensity progressively increased in developed countries in the last decades.

As the psychologists pointed out long ago, any differential of hedonic experience (pleasure or pain) induced by a specific event is short-lived and rapidly fades away. Any attempt at increasing the happiness of individuals appears thus condemned to defeat (this worrying effect is often called "hedonic treadmill” following Brickman and Campbell, 1971). This is true in particular of economic events. The utilitarian tradition focused mainly on non-durable consumption whose transient effect on happiness is obvious. Following Scitowsky (1976) we have to distinguish, however, between comfort goods whose contribution to happiness is particularly short-lived and stimulation goods that have a longer, and possibly persistent, impact on happiness as their consumption is related to the stimulation of individuals creativity. While the confessor of Henry IV complained for having been served for too long with his favored dish (partridge), a fan of Beethoven would not complain for having the opportunity of listening over and over again his masterpieces as each performance may reveal new delights. In the case of durable goods the distinction between comfort and stimulation goods is even more crucial. The rapid decline of pleasure given by the consumption of comfort goods leads to the frustrating attempt to progressively upgrading the comfort contents of the goods consumed to keep 
alive happiness, so triggering a form of consumerist addiction (Scitowski, 1976). On the contrary, stimulation goods may keep alive an increase in happiness much longer. While buying the last model of television or car brings about a short-lived differential of happiness, the purchase of a guitar or a book or a CD may have a much more durable impact on it. The hedonic treadmill contributes to the explanation of the happiness paradox but is insufficient to account fully for it since the existence of stimulation goods implies that an increase in income should translate in more happiness at least to the extent that consumption focuses on stimulation goods.

The "theory of livability" stresses the role of needs hierarchy as income growth satisfies the primary needs but not by itself the superior needs related to the self-realization of individuals (Veenhoven, 1984). This theory captures a further crucial factor that explains why income growth has a diminishing effect on happiness. As soon as the basic needs are satisfied, happiness cannot be kept alive simply by shifting to superfluous goods and luxury goods but only to superior goods that enhance the self-realization of individuals. Only by pursuing the latter course, happiness may improve in a sustainable way.

The results of the empirical research on happiness reviewed so far are not necessarily inconsistent with traditional utility theory. ${ }^{2}$ The causal factors already examined are insufficient, however, to fully explain the happiness-income paradox. Other explanations have thus been put forward that cannot be easily reconciled with traditional utilitarianism unless we are prepared to modify and extend it in a substantial way (for a recent attempt of this kind see Clark, A.E. P.Frijters, and M.A.Shields, 2006).

According to the "aspiration theory", suggested by Easterlin in his seminal paper (Easterlin, 1974), the happiness of economic agents depends not on the outcomes of their behavior alone, in particular their per capita income, but on the gap between aspirations of income $Y^{*}$ and effective income $Y$ :

$$
W^{*}=f_{2}\left(Y^{*}-Y\right), \quad f^{\prime}{ }_{2}<0
$$

Since desired income is considered to be a positive function of effective income, the gap is continuously reproduced ("satisfaction treadmill”). Whatever is the explanation of the

\footnotetext{
${ }^{2}$ According to the traditional point of view of economics, the total utility of an individual depends mainly on consumption and therefore is a growing function of per capita income. The slope of the function is progressively decreasing according to the law of diminishing marginal utility that is generally explained in terms of satiation and hierarchy of needs.
} 
dynamics of income aspirations, the elasticity of aspirations to increases of income is found to be close to one by most empirical estimations (Frey and Stutzer, 2002):

$$
\Delta Y^{*}=k(\Delta Y), \quad k \approx 1,
$$

from which we easily derive that $\Delta W^{*}=f_{2}\left(\Delta Y^{*}-\Delta Y\right) \approx 0$, i.e. that happiness does not tend to increase in consequence of an increase in per capita income.

A variant of this theory emphasizes the role of positional goods in explaining the continuous shift of aspirations (Frank, 1985; Hirsch, 1976). Since conspicuous consumption of positional goods is a zero-sum game, the attempt of keeping the social position by individuals increases aggregate and personal income by reducing leisure and giving incentives to more intense personal efforts without affecting aggregate satisfaction. This variant is strictly connected with the role of social factors and relative income since conspicuous consumption may be seen as the scarcity rent of socio-economic status (see section 3.2). Since the latter is in fixed supply, any conspicuous consumption generates negative externalities on other individuals. The aspiration theory in all its variants may thus account for the so-called "satisfaction treadmill” recalled above but cannot explain by itself the progressive decline of subjective happiness observed in many developed countries after WWII unless we assume a growing frustration of aspirations that remains groundless $(\mathrm{Ng}$, 1978). Moreover, the elasticity of aspirations to effective outcomes is unlikely to maintain a value close to one along all the life cycle of individuals. In particular it is plausible to assume that aged people have a progressively lower elasticity of aspirations to outcomes.

3.2. The role of relative income and social factors. After a threshold between $\$ 10,000$ and $\$ 15,000$, the influence of absolute income on happiness rapidly fades away, while the crucial role is taken over by relative income $Y^{R}$ and social relations $R$. As a matter of fact, unhappiness increases if the relative personal income of the individual $i$ diminishes relatively to the (average) per capita income of a reference group $j$ and vice versa. The most simple formalization is the following:

$$
W i^{*}=f_{4}\left(Y^{R}\right), \quad f_{4}^{\prime}>0,
$$

where $Y^{R}=Y_{i} / Y_{j}$ and $Y_{j}$ is the (average) per capita income of a reference group (the Joneses, colleagues, people with similar education or a similar job, and so on). This 
correlation holds also for more sophisticated measures of income inequality such as Gini or Theil indexes. The feelings of relative deprivation produced by differential access to positional goods depends not only on their signaling social ranking but also on the gap between different classes of income and wealth. Therefore, the increase of income inequality enhances the unhappiness of people. Since in most OECD countries income inequality slightly decreased up to the late 1970s, and then increased, this factor cannot explain by itself the behavior of self-reported happiness since WWII, although it may contribute to explain the worsening of the trend observed in many developed countries since the early 1980s.

Other related explanations stress the role of relational goods $R$ :

$$
W^{*}=f_{5}(R), \quad \quad f_{5}>0 .
$$

The category of relational goods has been introduced only recently in economic theory in order to capture the affective and communicative components of interpersonal relations the importance of which has recently emerged in economics in different fields, including the explanation of happiness (Nussbaum, 1986; Gui, 1996). These goods have characteristics quite different from those of ordinary goods as they are end in themselves, cannot be produced or consumed by a single individual but only simultaneously by at least two of them, while their value depends on the interaction between individuals under conditions of reciprocity (for a recent assessment see Gui and Sugden, 2005). Examples are love, friendship, and more in general direct personal social relations, i.e. not mediated by economic or political exchanges. ${ }^{3}$ Many empirical studies proved that relational goods play a crucial role in the determination of happiness while loneliness is negatively correlated with happiness (Deci and Ryan, 1985). Bruni and Stanca (2005) on the basis of World Values Survey (264.000 observations coming from 80 countries for the period 1980-2003) showed that there is a strong positive correlation between the length of time dedicated to relational activity (in the family, with friends, in voluntary service) and subjective happiness. Relational goods may have the nature of stimulation goods as they do not necessarily contribute to the comfort of individuals but appeal to their creativity. The

\footnotetext{
${ }^{3}$ The set of personal relations that support relational goods define the civic society (or community) not to be confused with society in its strict sense or set of impersonal relations mediated by the market and/or the political process. Economics has traditionally focused on society fully neglecting community, so loosing the opportunity of understanding the strong influence that relational goods have on the working of the economy and on the happiness of citizens (see Bruni, 2006a).
} 
contribution to happiness given by social interaction is higher when it is not motivated by self-interest. For example, the empirical evidence shows that altruism and voluntary service contribute to happiness (Frey and Stutzer, 2002; Bruni and Stanca 2005). According to many researchers, the progressive development of the market has displaced and suffocated the process of production and consumption of relational goods and this contributes to explaining the paradox of happiness (Bartolini and Bonatti, 2002). One economic reason underlying this process is a continuous alteration of the relative price of comfort goods that progressively decreased due to technical progress and standardization, while the costs of relational goods did not diminish or even increased (Bruni, 2006b). This led to a process of substitution of relational goods with cheap comfort goods. A case in point is the increasing time dedicated to television watching as a surrogate of relational activity: the empirical evidence shows that TV watching is positively correlated with hours of work and negatively correlated with happiness (Bruni and Stanca, 2005). The deterioration of relational goods in the last decades contributes to explain the happiness paradox, but its slow trend suggests that this factor is unlikely to explain by itself the paradox of happiness.

3.3.Other factors. The "theory of adaptation" maintains that individuals are characterized by a stable equilibrium state of happiness. When this state is perturbed by a positive or negative event the effects are only temporary as the individuals rapidly adapt to the new conditions (Brickman et al. 1978):

( 6 ) $\quad W_{i}^{*}=f_{6}\left(W^{*}{ }_{i}-X_{\mathrm{i}}^{*}\right), \quad f^{\prime}{ }_{6}>0$ when $W^{*}{ }_{i}-X_{\mathrm{i}}^{*}>0$, and $f^{\prime}{ }_{6}<0$ when $W^{*}{ }_{i}-X_{\mathrm{i}}^{*}<0$,

where $X_{\mathrm{i}}^{*}$ is the stable equilibrium point (or "set point") of happiness of the individual $i$. This process of adaptation contributes to explain the alleged independence of the characteristic happiness of individuals from the events of their experience. As for the determination of the equilibrium point, a few psychologists maintained that individuals have their own level of happiness that is independent of their experience and is firmly rooted in their own personality as established by genetic and psychogenetic factors $G$ (“theory of personality” or "set point theory”; see, e.g., Likken and Tellegen, 1996):

$$
\mathrm{W}_{\mathrm{i}}^{*}=f_{7}\left(G_{i}\right) \text {. }
$$


Although the importance of personality and genetic factors on happiness is well established, the strong version of this theory has been recently questioned by accurate empirical studies that show that personality factors explain only in part the variations of subjective indexes of happiness, and that in any case adaptation is not complete (Diener, 1996).

Another influential theory stresses the fact that the growth of per capita income produces negative externalities $E$ that deteriorate the happiness of citizen:

$$
W^{*}=f_{8}(E), \quad f_{8}^{\prime}<0 .
$$

An extensive literature documented huge environmental negative externalities $E$ in the postwar period (see, e.g., Borghesi and Vercelli, 2007 and literature therein cited. We have to mention in particular the depletion or deterioration of the environmental capital because of external diseconomies produced by income growth in consequence of pollution and exhaustion of environmental goods. In addition, we have to consider the deterioration of social capital produced by inequality and the growing influence of modern mass media (in particular television). ${ }^{4}$ This factor provides a crucial explanation of the happiness paradox but the quantification of its impact is strictly dependent on the list of relevant externalities and their evaluation, issues that are still very controversial (see section 6).

It is now widely accepted that unemployment reduces well-being, even after controlling for the associated fall in income (Clark, Frijters, and Shield, 2007):

$$
W^{*}=f_{9}(U), \quad f_{9}{ }_{9}<0 .
$$

Clark and Oswald (1994, p.655) conclude their accurate research on the effects of unemployment in the UK by asserting that "joblessness depressed well-being more than any other single characteristic". These results have been confirmed for many other countries (an early survey of the literature may be found in Darity and Goldsmith, 1996, and an articulated updating in Frey and Stutzer, 2002). The unemployed is victim of anxiety, anger and depression and suffers from a loss of self-esteem and social status and that may disrupt his/her familiar and social life. Unemployment, however, is not strictly correlated with the evolution of happiness in many countries. While the latter stagnated in

\footnotetext{
${ }^{4}$ According to Bartolini and Bonatti (2003) these negative externalities are a necessary mainspring of growth.
} 
many industrialised countries in the post-war period, in the same countries unemployment diminished in the 1950s and 1960s, increased in the 1970s and 1980s but diminished again in the 1990s and first 2000s. This diminution, however, was correlated to growing flexibility of labour markets and industrial relations that is likely to have contributed to declining job satisfaction. The strong correlation of unemployment with unhappiness is inconsistent with the widespread conviction that unemployment is never involuntary (see, e.g. Lucas, 1981, and, for a criticism, Vercelli, 1991; Frey and Stutzer 2002). This implies that policies meant to eliminate involuntary unemployment, in the absence of negative collateral effects, would increase the happiness of workers.

Another important determinant of happiness is the degree of education $I$ :

$$
W^{*}=f_{10}(I), \quad f^{\prime}{ }_{10}>0 .
$$

Along the whole life cycle a higher degree of education correlates with a higher degree of subjective happiness and the differential is independent of variations of per capita income (Easterlin, 2004). Education increases the set of enjoyable goods as it expands, e.g., the fruition of cultural goods (literature, classical music and opera, theatre, cinema, and so on). The higher is the level of education, the higher is the capability of appreciating creative and stimulating goods and activities that are much less subject to the hedonic and satisfaction treadmills. In addition the upgrading of the average level of education would contribute to the diffusion of well-informed preferences reducing unnecessary unhappiness (Scitovsky, 1976, Easterlin, 2004).The average level of education increased continuously in most countries since the WWII but apparently this did not contribute to an improvement of happiness, probably because also in this field the individual aspirations increased with the average level of education.

Finally, last but not least, we have to mention health $H$ as a major determinant of happiness. Frey and Stutzer (2002, p.56) remark that "when people are asked to evaluate the importance of various areas of their lives, good health obtains the higher rating”, so that:

$$
W^{*}=f_{11}(H), \quad f_{11}>0 .
$$

Since the impact of health on happiness is particularly important and quite complex we postpone its analysis to section 4 . 
3.4. Concluding remarks The determinants of happiness that we have considered so far do not exclude each other. Each of them captures an important causal factor of selfreported happiness. Although there is a serious problem of multicollinearity, for each of the factors considered there are empirical studies that argue in favor of their, at least partial, independence. We can thus summarize the acquisitions of the research surveyed above in the following way:

$$
W^{*}=F\left(Y, Y^{R}, Y-Y^{*}, G, R, E, I, U, H\right)
$$

where the partial derivatives with respect to each variable are assumed to have the same sign of the derivatives discussed above. Each of the capital letters that appear in the argument of the function $F$ may be considered as a vector of variables some of which have the dimension of flow and others of stock. So the happiness of people depends on their per capita income but also on their wealth, on their aspirations about both income and wealth, on flow externalities but also on stock externalities concerning the quantitative and qualitative characteristics of environmental and social capital, on flow exogenous variables (such as genetic shocks) and stock exogenous variables (such as the genetic endowment of people), on education and human capital, employment status and curriculum.

Of course we may add other variables in the argument of the happiness function (12). However, their role has been insufficiently explored or their independence inadequately supported by the empirical evidence. Possible exceptions could be leisure, inflation and institutional factors. Traditional utility theory considered work as generating disutility and leisure as generating utility (Argyle, 1996), but this is not generally true. An interesting work may contribute to happiness (Frey and Stutzer, 2002, and literature therein cited) while not all leisure activities contribute to happiness: bowling alone or watching the television may be a sign of solitude and depression (Putnam, 2000; Bruni and Stanca, 2005). So, the necessary disaggregation of leisure activities sends back to factors already considered such as social relations, absolute and relative income, health. Another important candidate to be included between the main happiness determinants is inflation. Frey and Stutzer (2002) found a negative correlation between inflation and happiness, while Di Tella and al. (2001) estimated the happiness trade-off between unemployment and inflation. We have doubts, however, about the genuine independence of its influence. Inflation acts mainly through modifications of absolute and relative income and disruption of social relations and sends back to the factors already considered above. Finally a few 
authors found a clear correlation between happiness and a few institutional factors (see in particular Frey and Stutzer, 2002). This line of research is inspiring but it is not yet clear to what extent the influence of institutions on happiness is independent of their impact on factors already considered such as social relations and relational goods.

We may thus interpret the function (12) as a fairly good representation of the main factors affecting happiness. This relation explains fairly well the happiness paradox. We may start from the observation that different individuals are characterized by different propensities to happiness descending from their personality and rooted in their genetic patrimony. We may agree that the amazing adaptive capabilities of the human beings assure a gradual convergence after shocks towards the individual characteristic happiness equilibrium. The latter cannot be conceived, however, as a stationary equilibrium since the positive and negative shocks are not completely reabsorbed in a reasonable time spell. Although the equilibrium hedonic state of individuals changes slowly, the memory of previous shocks may have a small but persistent impact on happiness. So the outcomes of individual behaviors (for example, per capita income) may have a persistent impact on happiness but this depends on the gap between the outcomes and aspirations since the latter tend to shift in the same direction of the outcomes. Adaptation, however, is not complete, apart from the particular case of positional goods (at the aggregate level). It is still difficult to explain the substantial lack of correlation between income and happiness in rich countries. A further contribution comes from the theory of needs hierarchy that introduces an evolutionary element in the analysis. We are still unable to explicate, however, why free time did not increase in the last decades. This may be accounted for by the role of positional goods and short-termism that increased the indebtedness of families and by the changes in labor markets that jeopardized the stability of jobs and the scope of workers rights (flexibility of labour markets and industrial relations).

In more abstract terms, income and wealth growth expand in principle the economic liberty of citizens as they expand the set of available economic options, and therefore, in principle, they enhance their happiness. The trouble is that in recent times this process came along with increasing constraints to the production and consumption of goods that reduce the economic liberty of citizens and their happiness so that the net effect is uncertain and depends on specific structural and policy circumstances.

Summing up, the paradox of happiness is not at all a paradox. We are not lacking an explanation; on the contrary we have perhaps an excess of explanations. They are all related to factors not taken into account by GDP statistics. We have to conclude that the 
real paradox is the persisting use of GDP statistics as the crucial index of citizens happiness (see section 6).

\section{The determinants of objective health: the second happiness paradox}

Since long, the epidemiological literature has found a strong correlation between measures of self-reported happiness and objective indexes of health, such as length of life (Palmore, 1969), heart disease (Sales and House, 1971), suicide (Koivumaa, Honkanen et al., 2001), strokes (Huppert, 2006). However, as soon as we compare the post-war trends of the most comprehensive objective health indexes (life expectations and mortality rates) with the trends of reported happiness in industrialized countries, a new happiness paradox emerges, similar to the one between happiness and income discussed above. As is well known, life expectations and mortality rates improved continuously in most countries after WWII, similarly to per capita income, while reported happiness did not follow a similar path. Also in this case the weak, sometimes slightly negative, correlation between health and reported happiness runs against the expectations and the opinion repeated by most people that health is a major determinant of happiness. In what follows we will call the weak and ambiguous correlation between general objective measures of health and self-reported happiness as the second (or happiness-health) paradox to distinguish it from the first (or happiness-income) paradox discussed in section 3. In order to explain the second happiness paradox, we need a preliminary analysis of the main health determinants in the light of the recent advances in social epidemiology.

4.1. The role of absolute income. The per capita income of a community (at a local, national or international level) is generally considered as a major determinant of its average health. This causal link is confirmed by an extensive set of empirical studies focusing both on cross-section and time series analysis. An increase in per capita income relaxes the budget constraints imposed by severe poverty that hinder the capacity of a person to prevent and cure a disease. In addition, an increase in average per capita income in a country is generally accompanied by higher expenditure in health programs, by better medical infrastructures, and by improving education levels favouring the diffusion of updated medical knowledge and know-how. The empirical literature shows that the relationship between absolute income $Y$ and health $H$ has a pattern very similar to that of the relationship between absolute income and happiness discussed in section 3.1: 
$H=\varphi_{1}(Y), \quad \varphi_{1}^{\prime}>0, \quad \varphi_{1}{ }^{\prime \prime}<O$

In cross-section studies it emerges that the health of the poor has a higher income elasticity than that of the rich. Cross-country evidence suggests that life expectancy increases with average per capita income in relatively poor countries, whereas this relationship tends to vanish for relatively rich countries (Preston, 1975). This can be clearly seen by looking at figure 1 that shows the relationship between life expectancy and per capita Gross Domestic Product (GDP) in year 2000 based on World Bank data referring to 175 countries. $^{5}$

fig. 1 about here

Similar results emerge also in single-country cross-section studies. Using a survey on health and income in Britain, Wilkinson (1992) finds that several health indicators increase rapidly as income rises from the lowest to the middle classes of income distribution, while no further health improvements occur at higher income levels. Similarly, using data from the National Longitudinal Mortality Survey in the USA, Deaton (2002) observes that the male (age adjusted) probability of death decreases rapidly as income grows at low family income levels, while it flattens out at high family income levels.

4.2 The role of relative income and social factors. The convex relation between absolute income and health implies that a reduction in income inequality would improve the average population health. In recent years several studies have argued that socioeconomic inequality has also an independent impact on individuals health, particularly in developed countries. A host of new evidence in different disciplinary fields clarified that, after a threshold of minimum income (at about $\$ 5,000$ ), ${ }^{6}$ income inequality emerges as a crucial determinant of health even when controlling for other factors including absolute income (Wilkinson, 1992). Similar results emerged in several other studies that focused on different groups of countries and periods of time (see Borghesi and Vercelli, 2007, chap.5 and literature therein cited).

\footnotetext{
${ }^{5}$ The regression line in the diagram describes how a logarithmic curve fits the data. This mathematical specification, however, overstates the higher part of the relation.

${ }^{6}$ Cornia et al. (2006) found a threshold slightly lower of $\$ 4,000$.
} 
The same relationship was found also at the local level. Comparative analysis across 50 US states, for example, showed a close relationship between inequality and mortality rates (Kaplan et al., 1996). Analogously, among the 282 US metropolitan areas the ones with the most unequal income distribution turned out to have the highest mortality rates (Lynch et al., 1998). These and similar results obtained in other countries suggest that relative income, independently of absolute income, has a crucial influence on health. The relative deprivation suffered by people in the lowest deciles of the income distribution may determine their exclusion from the social activities that promote or preserve health. Moreover, as several empirical papers have pointed out, relative deprivation may be a source of persistent stress, loss of self-esteem and chronic depression which tend to damage directly individuals' health (see Wilkinson, 2002). People compare themselves with reference groups around them (neighbours, co-workers, friends, relatives, and so on) and may suffer from chronic stress when the comparison with these benchmarks is unfavourable. $^{7}$ These psychological mechanisms, adversely affect people's health (see, e.g., Sapolsky, 1998; Brunner and Marmot, 1999). The underlying physiological mechanism is based on the activation of hormones that affect the cardiovascular and immune systems (ibidem, pp.15-16). The mechanism through which chronic stress jeopardises the health of individuals is very similar to economic "short-termism", i.e. the myopic emphasis on short-term objectives to the cost of jeopardising the achievement of longer-run objectives. In both cases all the available resources are mobilised to obtain a desired short-term goal even at the cost of jeopardising the sustainability of good performance in the longer term (see Borghesi and Vercelli, 2007)

The assertion that relative income has a crucial independent impact on population health came to be called in the epidemiological literature as "Relative Income Hypothesis” (from now on RIH) and may be expressed as follows:

$$
\text { (14) } H_{i}=\varphi_{2}\left(Y^{R}\right), \quad \varphi^{\prime}{ }_{2}>0 \text {, }
$$

where $Y^{R}$ is the relative income that may be measured in different ways (see section 3).

The empirical evidence suggests that inequality engenders mistrust and hostility with negative effects on people's health, the more so the more incomes are perceived to be unrelated or non-proportional to individual effort and merit. This may explain why the

\footnotetext{
${ }^{7}$ Deaton (2002) argues that this psychological mechanism plays a crucial role in causing stress to the agents and sets up a model assuming that each individual's stress is proportional to the total amount of income that goes to richer people in the community.
} 
most egalitarian developed countries tend to have the highest life expectancy (see Wilkinson, 2002, p.14). The close relationship between income inequality and mortality rates that is observed in cross-country studies emerges also in time series referring to single countries. $^{8}$

4.3 The role of other social factors. The empirical evidence shows that health is strongly affected by a series of social factors connected with relative income but in part independent of it. An early example of the role of relational factors is the famous example of Roseto in Pennsylvania, a small US town built by a group of Italian immigrants from the rural community of Roseto Valfortore in Italy (Kawachi and Kennedy, 2002). This case attracted the attention of epidemiologists since the 1950s because its inhabitants were characterized by much better health indexes than other US towns with similar economic and demographic characteristics. The only anomaly detected by researchers was that this group of immigrants had managed to retain their culture of origin characterized by a much more active social life. This anomaly gradually disappeared in the 1960s and 1970s as the culture of this town became increasingly homogenous with the American way of life and with it disappeared the favourable health differentials. Social epidemiologists, alerted by the case of Roseto, argued that the positive correlation between health indicators and social factors is a general and relevant one. We may summarize this series of social factors in terms of relational goods $R$ :

$$
\text { (14) } H=\varphi_{3}(R) \quad \varphi^{\prime}{ }_{3}>0 \text {. }
$$

The empirical evidence shows a clear positive correlation between interpersonal relations and health (see, e.g., Ryff and Singer, 2000). For example stress-related mortality of married people is significantly lower than that of people who are widowed, divorced and single (Cornia et al., 2007). In order to withstand physiological and psychological shocks, a crucial role may be played by the intensity and quality of social relations, and what is often called "social capital". ${ }^{9}$ In particular, the lack of social trust was shown to be positively and significantly correlated with mortality in the USA (Kawachi et al., 1997),

\footnotetext{
${ }_{9}^{8}$ Much of the relevant research has been collected in one volume (Kawachi et al., 1999).

9 Social relations are generally conceived as flow variables. However, they leave a persistent trace in terms of dispositions of people to new encounters and of facilities that reduce their costs. These persistent effects may accumulate in a stock that may be interpreted as a crucial component of social capital. See, e.g., Pugno (2007).
} 
with a correlation coefficient that ranges between 0.71 and 0.79 depending on the kind of social trust indicators used for the analysis. Analogously hostility was found positively correlated with mortality. For example, Williams et al. (1995) estimated that mean hostility scores of ten cities in the USA were strongly and significantly correlated with their mortality rates after adjusting for race, age, gender, income and education level of the individuals.

\subsection{The influence of environmental externalities on health The World Health} Organisation (WHO) has estimated that bad environmental conditions are directly responsible for about $25 \%$ of all cases of preventable illness all over the world (WHO, 1997). We have thus to consider negative environmental externalities $E$ as a further crucial determinant of health:

$$
\text { (16) } H=\varphi_{4}(E) \quad \varphi^{\prime}{ }_{4}<0
$$

Atmospheric pollution is considered the main cause of the large increase of respiratory diseases observed in recent years. Some particularly volatile pollutants such as fine dust (PM10), nitric oxide $\left(\mathrm{NO}_{\mathrm{x}}\right)$ and sulphur dioxide $\left(\mathrm{SO}_{2}\right)$ - discharged by cars traffic, heating, and manufacturing - can penetrate into the bronchioles, provoking asthma, bronchitis and emphysema (Worldwatch Institute, 1990). ${ }^{10}$ Besides respiratory conditions, atmospheric pollutants are often responsible for cardiovascular diseases since, once inhaled, they are carried round the body by the blood.

As for water pollution, the concentration of faecal coliform bacteria in water lacking efficient treatment, is an index of pathogenic agents responsible for diarrhoea, cholera, hepatitis, typhoid fever and other illnesses of the digestive system. Recent studies (WHO, 1997) have estimated that these diseases can be ascribed in $90 \%$ of cases precisely to the lack of clean water and to inadequate sanitation. Those worst affected are children in developing countries (where 95\% of water is untreated). ${ }^{11}$ Another factor of water pollution that has serious consequences for human health is the presence in water of heavy metals (such as lead, cadmium, mercury, arsenic and nickel) and polluting chemical products (such as PCB, DDT and dioxins). People ingest these elements by drinking water

\footnotetext{
${ }^{10}$ WHO (1997) estimates that atmospheric pollution is also directly responsible for $2 \%$ of cases of cancer.

${ }^{11}$ It has been estimated (WHO, 1997) that $88 \%$ of deaths due to intestinal diseases involve children under 15 years of age, a much higher incidence than the average number of deaths under 15 years of age due to other diseases (30\%).
} 
since they are difficult to remove under normal treatment processes, or when they eat fish where metals can accumulate. Various studies demonstrated that some heavy metals, such as nickel, cause serious damage to the nervous system, others, such as lead, mercury and arsenic, harm liver and kidneys. ${ }^{12}$ All heavy metals and many chemical pollutants are also thought to be responsible for tumour formation. Furthermore, water pollution in combination with atmospheric pollution can modify the habitat of some ecosystems (temperature, humidity, vegetation density, and so on). This can enhance the survival and spreading of insects that are particularly harmful because of the diseases they may carry. This is the case of mosquitoes which transmit various diseases including malaria. This serious disease is thought to be responsible for a million deaths among children aged under five years and is becoming an increasingly serious problem, especially in sub-Saharan Africa where 90\% of the world's malaria cases are concentrated (WHO, 1997).

Many chemical, biological and radioactive pollutants tend to settle on the soil, contaminating both the crops planted there and the resultant agricultural products. In addition, soil pollution damages the health not only of farmers who work contaminated land and of children playing there, but also of the surrounding population since dust from the polluted area can be carried elsewhere by the wind. Direct contact with contaminated soil and with the numerous microbes and parasites contained in it is particularly harmful for children who are extremely vulnerable. ${ }^{13}$ Not only pollution but also overworking the soil can damage the health of the population. This is particularly true for rural families in poor countries which are dependent on the food they produce. The attempt to achieve a minimum level of subsistence sometimes drives rural people to over-exploit land reducing its fertility. This in turn reduces calorie and protein intake on the part of the farmers, reducing their productivity and making them more vulnerable to diseases. The loss of income resulting from illness and lower land and labour productivity increases the indigence of the farmers generating a vicious circle between poverty, environmental degradation and population health.

\subsection{Other factors: medical technology, instruction, unemployment, genetic factors}

Medical technology $T$ played a crucial role in the progressive improvement of the objective indexes of health in the last century:

\footnotetext{
${ }^{12}$ See, e.g., Conservation Foundation (1992).

13 This may contribute to explain, for example, the high incidence of neonatal tetanus in the poorest areas of the developing countries.
} 


$$
H=\varphi_{5}(T), \varphi^{\prime}{ }_{5}>0 .
$$

In order to get insights on the other determinants of health we have to study the deviations from this common trend due to specific factors.

The empirical evidence shows that another important determinant of health is education. The relationship between education $I$ and health is strongly non linear as it increases sharply by moving from primary to secondary education and above:

$$
H=\varphi_{6}(I), \quad \varphi_{6}^{\prime}>0, \quad \varphi^{\prime \prime}{ }_{6}<0 .
$$

In particular, most empirical studies on both developed and developing countries found that the level of education of mothers is a major determinant of health of all family members, the children in particular. Educated parents manage better the household resources in order to improve family health, exploiting their deeper knowledge of health determinants and avoiding unhealthy practices and lifestyle (Cornia et al., 2007, and literature therein cited).

Another crucial factor of health is unemployment $U$ :

$$
H=\varphi_{7}(U), \quad \varphi^{\prime}{ }_{7}<0
$$

Loss of employment, especially if unanticipated and in the absence of a public safety net, and the persistence of unemployment heavily affect health. It is also an obstacle to marriage and stable life. The feelings of frustration and anger nurtured by unemployment tend to disrupt trust and social relations increasing crime and violence. According to epidemiological studies, unemployed individuals face a greater risk of mortality than the employed. Similar effects are produced by the instability of both jobs and industrial relations (Warr, 1999).

Also genetic factors $G$ may have a sizable impact on health:

$$
H=\varphi_{8}(G)
$$

We have to distinguish two main factors: mutation of genes and polygenic inheritance, i.e. the specific combination of normal genes that confers a bias towards specific chronic 
diseases, such as high pressure, diabetes, and cancer. Research has found about 4,000 mutant genes that may cause diseases such as sickle-cell anemia, cystic fibrosis, and Huntington's disease (Tarlov and Peter, 2000, p.x). Epidemiologists maintain that the relative incidence of these diseases is fairly low as it did not exceed a value around $5 \%$ of the total (ibidem). In the case of polygenic inheritance, for a chronic disease actually to manifest itself, concomitant circumstances have to concur, such as health-damaging behaviours or socio-economic factors. We may thus consider its impact important but only in the distribution of chronic diseases rather then in their aggregate incidence on population health.

Finally, individual health is heavily influenced by personal lifestyle and behavioural habits such as the time devoted to sport, open-air activity and periodical medical checks, nutritional habits, smoking, etc. In this regard, it should be noted that an increase in per capita income is sometimes related to a rise in health-damaging behaviours that may partially counterbalance the positive effects of higher income. Poor diet and excessive tobacco and alcohol consumption, for instance, may explain why in some Central and Eastern Europe countries (e.g. Hungary and Slovakia) male life expectancy increased only slightly or remained unchanged in the last few decades despite an increase in per capita income (OECD, 2001). Moreover, some developed countries show lower average health status than some developing countries due to sedentary life habits and (over)consumption of unhealthy fast-food as a consequence of stressful work timetables. ${ }^{14}$ Finally, an increase in the number of cases of anorexia has been observed in most developed countries, especially in the young generation that is particularly exposed and sensitive to the beauty standards proposed by the mass-media that induce severely health-damaging behaviours. This represents a particularly interesting new example of a complex link between health and happiness that would deserve further analysis in the future. However, we do not include this set of factors in the function of health since for the time being it would be difficult to measure their impact with a reliable index. As for their impact on happiness we can assume that it is exerted through health.

4.6. Concluding remarks. The main determinants of health considered in the epidemiological literature do not exclude each other. We can thus summarize the function that explains the behaviour of the health status in the following way:

\footnotetext{
${ }^{14}$ As it is well known, at the world level the number of individuals affected by obesity has recently overcome those suffering malnutrition.
} 


$$
H^{*}=\Phi\left(Y, Y^{R}, G, R, E, I, U, T, W\right)
$$

where we assume that the partial derivatives for each factor have the same signs discussed above. The capital letters that appear in the argument of the function $\Phi$ should be interpreted as vectors of variables some of which have a flow dimension and others a stock dimension. So the health of people depends on their absolute income but also on their wealth, on relative income and relative wealth, on alterations to genetic traits (because of cosmic or anthropogenic radiations) and the genetic patrimony of individuals, on flow environmental externalities (e.g. polluting emissions) and accumulated stocks of their effects (such as the concentration of GHGs in the atmosphere), on relational goods and social capital, on training and degree of education, change of working status and curriculum.

Also in this case, of course, other health determinants that are significant for particular countries and periods may be included among the arguments of the function. However, we preferred to include only the factors that have been systematically analysed in the epidemiological literature and have found a fairly robust empirical support.

\section{Interaction between happiness and health: the twin paradoxes}

Although the literature on the causes of subjective happiness and objective health developed quite independently, they pointed out about the same list of main determinants. This strong analogy emerges immediately from a comparison between the two comprehensive functions ( 12 ) for happiness and ( 21 ) for health. It is striking that two streams of literature pursued independently by different groups of researchers focused mainly on the same kernel of systematic factors finding similar patterns of correlation for each of them. Of course, the emphasis, the language and the conceptual framework are often different but it is difficult to find serious divergences in the basic results of the analysis. The only substantial differences emerging from a prima facie comparison of the two general equations is the absence of aspirations and the presence of the health technology in the health equation. As for frustrated aspirations the epidemiological literature confirms its crucial role in the psycho-physical health of individuals (Marmot, 2004) but its role is not restricted to per capita income. As for the role of health technology, its effects on happiness are captured by the presence of health among the arguments of the happiness equation and does not need to appear explicitly. Analogously, 
the effects of technical change in general (i.e. not circumscribed to medical technical change) is largely captured by income in the happiness equation so that technology in general does not need to be considered explicitly in both the health and happiness equations.

We are now in the position of trying to explain the second happiness paradox. Why the continuous improvement of objective health after WWII in developed countries did not translate in increasing self-reported happiness? A possible explanation is that the progressive increase in life expectancy and reduction of mortality rates determined a continuous ageing of the population that is negatively correlated with self-reported health and therefore also with subjective happiness. The empirical evidence shows that the importance of health is declared to increase with age while self-reported health declines; this should reflect negatively on happiness, taking account of the high correlation between subjective happiness and self-reported health. We believe that this causal link may have had some influence on stagnating happiness in the post-war period but its impact, evaluated in the light of existing empirical evidence, is unlikely to have been decisive. In fact, according to existing empirical evidence, happiness declines from youth to working age but increases again, though moderately, since around the age of retirement (FreyStutzer, 2002). This may be related to increasing free time of senior people, decreasing responsibilities, downsizing of aspirations and, maybe, natural selection of the healthier and happier individuals. We have to conclude that the negative effect exerted by ageing on health is more than compensated by other factors correlated with age.

There are compelling reasons to suggest that the comprehensive objective health indexes mentioned above (life expectations and mortality rates) do not reflect well the effects exerted by health on subjective happiness. In particular, there are specific health indexes strictly correlated with self-reported unhappiness, such as frequency of depression and suicides, that increased progressively in the post-war period (Kawachi and Kennedy, 2002). Subjective health and subjective happiness depend not only on the length of life but crucially also on its quality. A long life is not necessarily a happy life. ${ }^{15}$

By comparing the determinants of happiness and health we may shed further light on their mutual relationship as well as on the twin paradoxes mentioned above. There is no doubt that different individuals are characterized by a different health status rooted in their genetic patrimony. The health status is characterized by homeostatic processes that assure

\footnotetext{
15 This is well known since long. In the island of Luggnagg visited by Gulliver in one of his travels, some of the inhabitants (Struldbrugs) are very unhappy because they become older and older but cannot die (Swift, 1726).
} 
its substantial stability through time. Such a fairly stable resting point cannot be considered as a stationary equilibrium since shocks may leave a permanent trace that slowly fades away but does not disappear. The average health status of a population depends basically on the evolution of medical technology and its infrastructures. However, there are substantial deviations from the average trend that depend on the quality of relational goods and social capital, on the availability and quality of environmental goods and jobs, as well as the subjective happiness of people.

The cross-section correlation between per capita income and health is very similar to that between per capita income and happiness. In both cases we have a concave correlation quite steep for low cohorts of income and fading away after a certain threshold. The thresholds are apparently different: between \$4,000 and \$5,000 in the case of health and between $\$ 10,000$ and $\$ 15,000$ in the case of happiness (see retro sections 3 and 4). So, notwithstanding the variance of both thresholds estimations, the threshold for health is consistently lower than that for happiness. In addition, in the case of health the correlation is steeper, almost vertical below the threshold, and almost flat beyond it, while in the case of happiness its marginal rate of change is more gradual as income grows. This empirical evidence is consistent with the hypothesis that the hierarchy of needs plays a crucial role in determining both subjective happiness and health. Up to the threshold mentioned above, an increase of income removes the constraints to the satisfaction of a few basic needs (food, dwelling, access to safe water and sanitation) that have a strong impact on health. This threshold is quite low because the satisfaction of these basic needs is strongly subsidized in most countries. Once these needs are satisfied, new needs emerge whose satisfaction improves health only marginally, but may still significantly improve happiness up to the second threshold. Beyond the latter, a further increase in absolute income does not seem to have a sizeable impact on either happiness or health (Frey and Stultzer, 2002). In both cases, after the specific threshold, the crucial causal role is taken over by relative income and social relations. As soon as the problem of survival is solved, the attention focuses on the perceived social status. This does not imply that social status is not important in poor communities such as the favelas of Brasil or the remote villages of Equatorial Africa or rural China (see Clark, Frijters, and Shields, 2006). The effects of relative deprivation, however, are overwhelmed up to the first threshold by the effects of absolute deprivation. The basic aspirations are set by the will to "keep up with the Joneses” while the Joneses try hard to keep the distances. Relative deprivation and frustrated aspirations generate stress and are sources of chronic and psychosomatic maladies. Another important source of 
happiness and health are the social relations entertained within the family, with friends and other members of the communities to which the individual belongs by choice or birth. The deterioration of relational goods is thus another important source of unhappiness and health degradation. Finally, the environmental negative externalities of growth affect directly in a negative way both happiness and health. In addition they force defensive expenditures that are to be subtracted from happiness-improving incomes.

\section{Indexes of happiness and health: shortcomings and policy implications}

The twin paradoxes of happiness emerge from a complex interaction between the etiological and semeiotic processes of well-being. In the light of the preceding analysis we may say that the twin paradoxes have a very simple common basic explanation in the flawed standard semiotics of both happiness (per capita income) and health (life expectancy and mortality rates) exactly because they fail to take account of the etiology of health and happiness. As we have ascertained, both the objective indexes of happiness and health are very poor indexes respectively of subjective happiness and subjective health as both are merely quantitative indexes and ignore the quality of life that plays a crucial role in human well-being and health. Therefore, the principal conclusion that descends from the preceding analysis has to emphasize the improper use of these “objective” indexes of well being (GDP) and health (life expectancy and mortality rates).

In particular, we should try hard to emancipate economic policy from the unjustified obsession for income growth. The quality of income turns out to be much more important than its crude quantitative measures adopted in national accounts. The latter are fraught with serious shortcomings that have been pointed out since long. First of all, the exhaustion of natural resources as well as the deterioration of natural and social capital are not registered by GDP accounting. In addition, defensive expenditure forced by the need of avoiding or offsetting environmental and social diseconomies are registered as addition to GDP. So, in order to obtain more reliable indexes of well-being, we should adjust the aggregate index of production and personal earnings in such a way to take account of defensive and compensative expenditures (that should be subtracted from genuinely disposable incomes) as well as environmental and social externalities. The revision of the general indexes of well-being could draw inspiration from the following line of reasoning. Per capita income is a rough index of economic freedom, rather than of well-being, to the extent that it defines the extension of the set of viable economic opportunities. Of course, genuine economic freedom so defined is likely to translate in well being if judiciously 
exercised by a rational agent unaffected by cultural and social constraints that distort his/her choices. In developed countries, however, the growth of income did not go hand-inhand with the expansion of personal economic freedom since part of it (roughly corresponding to the growing part of income) happened to be already committed to specific expenditures either because it derived from the substitution of free goods with privatized expensive goods and partly because it was forced by the need of compensating negative environmental and social externalities.

The awareness of the serious shortcomings of aggregate national accounts led to the elaboration of alternative indexes that aimed to correct some of the shortcomings. One of the most interesting early contributions was a novel index of social well-being called NEW (Net Economic Welfare) suggested by Nordhaus and Tobin (1973). This index adds to income goods and services produced outside the market (free environmental goods, domestic and voluntary work as well as leisure). At the same time, the index subtracts from traditional income different kinds of "bads", i.e. negative externalities produced by the deterioration of environmental and social capital. The empirical applications showed that the NEW has been permanently higher than GDP but has grown more slowly in the postwar period in industrialized countries. Subsequent studies confirmed that the rate of growth of defensive and compensative expenditures in developed countries has been in the last decades much higher than the rate of growth of GDP (three times higher in Germany in the period 1970-1980, according to the estimations of Leipert, 1989).

An interesting more recent contribution came from Daly and Cobb (1989). Their suggested index, the ISEW (Index of Sustainable Economic Welfare) refined the NEW by including a few further social indicators of unhappiness (such as inequality, costs related to commuting, car accidents and urban congestion, uninformative publicity, defensive and compensative expenditures related to health and instruction) as well as further environmental costs not considered in the NEW (such as depletion of natural capital, costs of pollution including those produced by anthropogenic climate change). ${ }^{16}$ The application of ISEW to the post-war US growth gave results very interesting from the point of view of the happiness paradox. While the US GNP increased from 1951 to 1986 at an average rate of $1.90 \%$, the ISEW grew much less (0.53\%). In addition, the growth of ISEW became negative since the early 1970s (-0.14\%). The main reason of this worsening lies in the accelerating deterioration of social indicators, while the contribution of the environmental

\footnotetext{
${ }^{16}$ Strangely enough the costs implied by waste production and disposal, the most rapidly growing environmental externality, is not included in the index.
} 
factors appears stationary. We can claim with hindsight that the negative contribution of environmental externalities to sustainable well-being was under-estimated by Daly and Cobb at least in the case of climate change whose gravity emerged only later, and in the case of the waste disposal externalities that are not considered by them. We may conclude that a crucial explanation of the first happiness paradox should be found in the distortions of GDP as index of well-being.

Unfortunately, neither these nor other new indexes of well-being more comprehensive than GDP gathered sufficient consensus to be systematically computed and updated. International Organizations advocated the systematic adoption of environmental and social accounting to correct and/or supplement traditional national accounting. National accounting institutions moved in this direction with different degrees of energy and in different directions. The consequence is that at the moment we do not have a visible and recognized alternative to GDP as objective index of happiness. A partial exception is the "index of human development”, introduced in 1990 by Sen, ul Haq, Ranis and Desai on the basis of Sen's capacity theory. As is well known, this index is made up of income per head, life expectancy at birth and average degree of education (measured by an index of literacy and the combined primary, secondary and tertiary school gross enrollment). The index of human development is systematically published since then by the United Nations Development Programme in its yearly Human Development Report. Although this index goes in the right direction, it is still too simplistic to be a reliable measure of well-being. ${ }^{17}$

It is interesting to observe that the indexes of well-being that try to go beyond the limitations of the traditional indexes of income typically include the same determinants considered in the literature on happiness. In the future these two literatures should interact more systematically in order to build up a new welfare (or better well-being or happiness) economics. This is starting to happen. Some researchers in the field of happiness have advocated the systematic adoption of national well-being indexes based on the recent advances in the happiness literature, to complement traditional GDP and other national accounts indexes (see in particular Kahneman and Krueger, 2006).

As for the indexes of health we should gather in a continuous and systematic way data on self-reported health in order to understand better the role of subjective perception of health and its relationship with objective health. The quantitative indexes of health, in their turn, should be corrected in order to take account of the quality of life. The existing

\footnotetext{
${ }^{17}$ Sen himself defined it as a "vulgar measure" that, however, may pave the way to more sophisticated measures of well-being, some components of which are already systematically registered in the Human Development Report.
} 
quality-adjusted indexes of health go in the right direction but should be further improved and systematically computed and publicized (Hansen and Østerdal, 2006).

\section{Concluding remarks}

In this paper we aimed to contribute to a strategy of cross-fertilization between the two rapidly growing research fields on the socio-economic determinants of happiness and health. Although these two research streams developed separately, they are characterized by strong structural analogies that are rich of potential insights and call for more interaction between them. The empirical literature confirms that health is a major determinant of subjective happiness and that the converse is also true. We have then ascertained that the other main determinants of subjective happiness and objective health have a common kernel and that the specification of their causal influences is very similar even in their functional form. We noticed that, notwithstanding this strong analogy, the behavior of subjective happiness and objective health are weakly correlated in developed countries. In these countries the general objective indexes of health (life expectancy and mortality rates) progressively improved in the post-war period while the subjective indexes of happiness did not improve in the same period. We called this prima facie surprising result as the second happiness paradox. We found a crucial explanation of the twin paradoxes of happiness in the shortcomings of the general objective indexes of well-being (income) and health (life expectancy and mortality rates) since both classes of measure do not take account of the quality of life that plays a crucial role in self-reported happiness of individuals and in their health.

The cross-fertilization between the happiness and health literatures may shed new light also on the complex issues raised by the choice of a policy strategy meant to improve happiness and health. The assumption of objective policy targets different from their subjective counterpart requires a sound understanding of the reasons of the deviations and a wide political consensus based on such understanding. Although these problems are far from being solved, we cannot ignore the policy implications of the happiness literature.

A common inference from the happiness literature is that economic growth per se is loosing importance in developed countries and should not be the primary goal of policy. This goes against the mainstream conviction, that has been recently confirmed by very influential economists, that economic policy should continue to focus on the maximization of income growth (see, e.g., Benjamin Friedman, 2006, and Bhagvati, 2005). A further growth of income could help us to conquer poverty, provided that its quality actually 
improves the well being of citizens. The incentives to growth should thus be directed in such a way to reduce poverty, provided that the production and structure of income aim at the happiness of people.

As for income distribution the happiness literature rejects the conventional wisdom that inequality is an incentive for growth or a disagreeable but inevitable collateral consequence of growth. Redistributing income from the rich to the poor would thus reduce both income and health inequalities improving the average health of the population, since the latter would benefit the health of the poor much more than it would affect the health of affluent people. A policy intervention of this kind would require a continuous and consistent support policy measures directed to improve the distribution of income, such as progressive taxation, social transfers to disadvantaged people and facilitated access to services to poorer people. The so-called welfare state was built, and progressively strengthened in the 1950s and 1960s, exactly for these aims. The happiness literature suggests that we should try to implement a new Welfare State capable of circumventing the mistakes of the past by increasing its efficiency and by strengthening at the same time its role of social insurance. The New Welfare State should also invest in social capital by providing the necessary material and immaterial infrastructures. As for material infrastructures, an urban design characterized by many squares and meeting places, an intense cultural life, and a salubrious environment would improve both happiness and health. As for immaterial infrastructures, the availability of a network of services and social facilities may reduce stress and morbidity.

Finally the analysis of the twin happiness paradoxes confirms that policies directed to invest in environmental and social capital, as well as in education, in culture and creative goods are likely to improve both health and happiness of the population. As for unemployment, policies meant to eliminate involuntary unemployment could increase happiness.

Summing up, both happiness paradoxes confirm that we should move towards a more egalitarian and solidaristic kind of growth, as measured not by GDP statistics but by more comprehensive indexes of well-being. 
Relationship between per capita GDP and health:

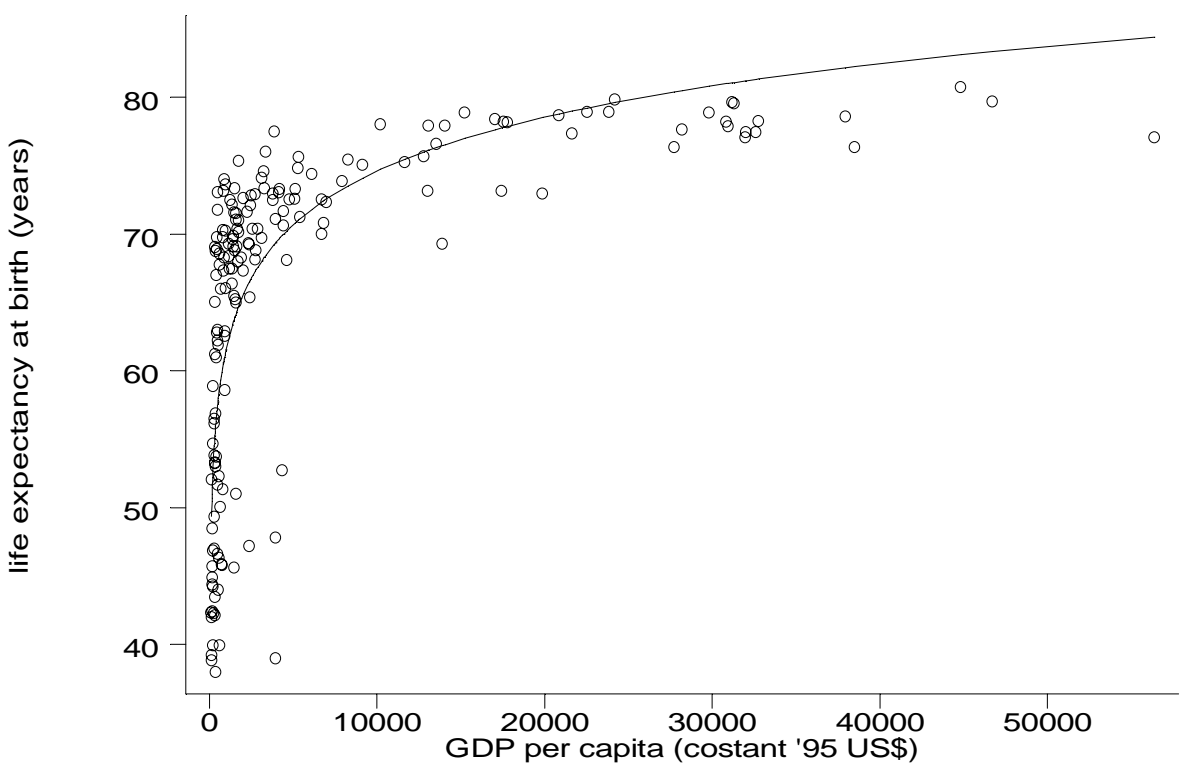

Fig.1

Source: authors’ elaboration on World Bank data

\section{References}

Argyle, M., 1996, The Social Psychology of Leisure, Penguin, New York.

Bartolini, S. and L.Bonatti, 2002, Environmental and Social Degradation as the Engine of Economic Growth, Ecological Economics, vol.41, pp.1-16

Bartolini, S and L. Bonatti, 2003, Endogenous Growth and Negative Externalities, Journal of Economics, vol.79, pp.123-144.

Bhagwati, J. , 2004, In Defense of Globalization, 2004, Oxford University Press, Oxford

Borghesi, S. and A. Vercelli, 2007, Global Sustainability, Palgrave-McMillan, London, forthcoming.

Brickman, P., Campbell, D.T., 1971, Hedonic Relativism and Planning the Good Society, in M.H. Apley, ed., Adaptation-level theory: a Symposium, Academic Press, New York, pp.287-302.

Brickman, P., Coates, D., Janoff-Bulman, R., 1978, Lottery Winners and Accidents Victims: Is Happiness relative?, Journal of Personality and Social Psychology, vol.36,, pp.917-927

Bruni, L., 2006a, Civil Happiness. Economics and Human flourishing in historical perspective, Routledge, Oxford and New York. 
Bruni, L and P.L. Porta, 2005, Economics and Happiness. Framing the analysis, Oxford University Press, Oxford.

Bruni, L., and L. Stanca, 2005, Watching Alone. Happiness and Television, Working Paper, University of Milan-Bicocca.

Brunner, E., Marmot, M., (1999), Social organization, stress, and health, in Marmot, M.G., and Wilkinson, R.G., eds., Social Determinants of Health, Oxford University Press, Oxford.

Cornia, G.A., Rosignoli, S., Tiberti, L., 2007, Globalisation and health: impact pathways and recent evidence, manuscript

Clark, A.E., Frijters, P. and M.A. Shields, 2006, Income and Happiness: Evidence, Explanations and Economic Implications, manuscript.

Clark, A.E., and A.J., Oswald, 1994, Unhappiness and Unemployment, Economic Journal, vol.104. pp.648-659.

Conservation Foundation, 1992, State of the environment, Washington D.C.

Daly, H.E., Cobb, J., B., jr., 1989, For the Common Good, Beacon Press, Boston.

Darity, W., and A.H. Goldsmith, 1996, Social Psychology, Unemployment and Macroeconomics, Journal of Economic Perspectives, 10 (1), 121-40-

Deaton, A., (2002), Health, inequality and economic development, Journal of Economic Literature, 41, 113-58.

Deci, E.L., and R.M. Ryan, 1985, Intrinsic Motivation and Self-Determination in Human Behaviour, Plenum Press, New York.

Diener, E., 1996, Traits Can Be Powerful, but Are not Enough: Lessons from Subjective Well-being, Journal of Research in Personality, vol.30, n.3, pp.389-399.

Di Tella, R., R.J. MacCulloch, and A.J. Oswald, 2001, Preferences over Inflation and Unemployment: Evidence from Surveys of Happiness, American Economic Review, 91, 1, 335-41.

Easterlin,, R.A., 1974, Does Economic Growth Improve the Human Lot? Some Empirical Evidence, in P.A. David, W.R. Melvin, eds., Nations and Households in Economic Growth: Essays in Honour of Moses Abramovitz, Academic Press, New York, pp.89-125.

Easterlin, R.A., 2001, Income and happiness: towards a unified theory, Economic Journal, vol.111, pp.465-484.

Frank, R.H., 1985, Choosing the right Pond, Oxford University Press, New York

Frey, B.S., and A. Stutzer, 2002, Happiness and economics, Princeton University Press, Princeton.

Friedman, B, 2006, The Moral Consequences of Economic Growth, Alfred A. Knopf, New York.

Gui, B., 1996, On relational goods: strategic implications of investment in relationships, International Journal of Social Economics, 23 (10/11), 1996, pp.260-278.

Gui, B., and Sugden, R., eds., 2005, Economics and Social Interaction: Accounting for Interpersonal Relations, Cambridge University Press, Cambridge.

Hansen, K.S., Østerdal, L.P., 2006, Models of Quality-Adjusted Life Years when Health Varies Over Time: Survey and Analysis, Journal of Economic Surveys 20 (2), 229255.

Hirsch, F., 1976, The Social Limits to Growth, Harvard University Press, Cambridge, Mass.

Huppert, F., 2006, Positive Emotions and Cognition: developmental Neuroscience and Health Perspectives, in J. Forges, ed., 2006, Hearts and Minds: Affective Influences on Social Cognition and Behaviour, Psychology Press, Philadelphia 
Kaplan, G.A., Pamuk, E.R., Lynch, J.W., Cohen, R.D., Balfour, J.L., (1996), Inequality in income and mortality in the United States: analysis of mortality and potential pathways, British Medical Journal, 312, pp.999-1003.

Kahneman, D., 1999, Objective Happiness, in D. Kahneman, E. Diener, and N. Schwartz, eds., 1999, Well-being: Foundations of Hedonic Psychology, Russel Sage Foundation, New York.

Kahneman, D. and A.B. Krueger, 2006, Developments in the measurement of subjective well-being, Journal of Economic Perspectives, vol.22, pp.3-24.

Kahneman, D. and J. Riis, 2005, Living, and thinking about it, two perspectives, in Huppert, F.A., Kaverne, B. and N. Baylis, The Science of Well-being, Oxford University Press.

Kawachi, I, Kennedy B.P. (2002) The Health of Nations: Why Inequality Is Harmful to Your Health, The New Press, New York.

Kawachi, I., Kennedy, B.P., Lochner, K., Prothrow-Stith, D., (1997), “Social capital, income inequality and mortality”, American Journal of Public Health, 87, pp.14911498.

Kawachi, I., Kennedy, B.P., Wilkinson, R.G., (1999), Income Inequality and

Health. Vol. I. The Society and Population Health Reader, New Press, New York.

Koivumaa-Honkanen, H., Honkanen, R., Viinamaeki, H., Heikkilae, K., Kaprio, J. and Koskenvuo, M., 2001, Life satisfaction and suicide: a 20 year follow-up study, American Journal of Psychiatry, vol.158, pp.433-439.

Layard, R., 2006, Happiness: Lessons from a New Science, Penguin, London.

Leipert, C., 1989, National Income and Economic Growth: The Conceptual Side of Defensive Expenditures, in Journal of Economic Issues, 3.

Likken, D., and A. Tellegen, 1996, Happiness is a Stochastic Phenomenon, Psychological Science, vol.7, n.3, pp.180-189.

Lucas, R., 1981, Studies in Business-Cycle Theory, MIT Press , Cambridge, Mass.

Lynch, J., Kaplan, G.A., Pamuk, E.R., Cohen, R.D., Heck, K.H., Balfour, J.L., Yen, I.H., (1998), "Income inequality and mortality in metropolitan areas of United States", American Journal of Public Health, 88, pp.1074-1080.

Marmot, M., 2004, Status Syndrome, Henry Holt, New York.

Ng, Y.K., 1978, Economic Growth and Social Welfare: the Need for A Complete Study of Happiness, Kyklos, vol.31, n.4, pp. 575-587.

Nordhaus, W.D., and J. Tobin, 1973, Is Growth Obsolete? in M. Moss, ed., The Measurement of Economic and Social Performance. Studies in Income and Wealth, 38, National Bureau of Economic Research.

Nussbaum, M., 1986, The Fragility of Goodness: Luck and Ethics in Greek Tragedy and Ethics, Cambridge University Press, Cambridge.

OECD - Organisation for Economic Cooperation and Development, 2001, Health at a glance, Paris

Palmore, E, 1969, Predicting longevity: A follow-up controlling for age, Journal of Gerontology, vol.39, pp.109-116

Pugno, M., 2007, The subjective well-being paradox: a suggested solution based on relational goods, in Bruni, L., and P.L.Porta, eds., Handbook on the Economics of Happiness, pp. 263-289, Elgar, London

Preston, S.H., (1975), "The changing relation between mortality and level of economic development”, Population Studies, 29, pp.231-248.

Putnam, R., 2000, Bowling Alone: the Collapse and Revival of American Community, Simon and Schuster, New York.

Ryff, C.D., and B. Singer, 2000, Interpersonal flourishing: A positive health for the new millenium, Personality and Social Psychology Review, 4, 30-44 
Sales, S.M., and J. House, 1971, job dissatisfaction as a possible risk factor in Coronary Heart Disease, Journal of Chronic Diseases, vol.23, pp.861-873.

Sapolsky, R.M., (1998), Why zebras don't get ulcers. A guide to stress, stressrelated disease and coping, $2^{\text {nd }}$ edition, W.H.Freeman, New York.

Scitowsky, T., 1976, The Joyless economy: An Inquiry into Human Satisfaction and Dissatisfaction, Oxford University Press, Oxford

Sen, A.K., 1987, On Ethics and Economics, Oxford University Press, Oxford.

Stigler, G.J. and G.S. Backer, 1977, De Gustibus Non Est Disputandum, The American Economic Review, 67, 2, 76-90.

Oxford

Swift, Jonathan, 1726, Gulliver's travels, ed. 2005, Oxford University Press,

Tarlov, A.R. and R.F. St. Peter, eds., 2000, The Society and Population Health

Reader, Volume II, A State and Community Perspective, The New Press, New York.

Veenhoven, R., 1984, Conditions of Happiness, Kluwer Academic, Dordrecht, The Netherlands

Vercelli, A, 1991, Methodological Foundations of Macroeconomics. Keynes and Lucas, Cambridge, Cambridge University Press

Warr, P., 1999, Well-Being and the Workplace, in D. Kahneman, E. Diener, and N. Schwarz, 1999, The Foundations of Hedonic Psychology, Russel Sage Foundation, New York, 392-412.

Wilkinson, R.G., (1992), Income distribution and life expectancy, British Medical Journal, vol.304, pp.165-168.

Williams, R.B., Feaganes, J., Barefoot, J.C., (1995), Hostility and death rates in 10 U.S. cities. Psychosomatic Medicine, 57(1), p.94.

WHO - World Health Organisation, (1997), Health and Environment in Sustainable Development: Five Years after the Earth Summit, Geneva.

Worldwatch Institute, State of the world 1990, Norton, New York, 1990. 